\title{
Catalytic wet air oxidation of methylamine over supported manganese dioxide catalysts
}

\author{
France Schmit ${ }^{\mathrm{a}, \mathrm{b}}$, Laurence Bois ${ }^{\mathrm{b}}$, Fernand Chassagneux ${ }^{\mathrm{b}}$, Claude Descorme ${ }^{\mathrm{a}, *}$ \\ a Institut de recherches sur la catalyse et l'environnement de Lyon (IRCELYON), 2 Av. Albert Einstein, 69626 Villeurbanne, France \\ ${ }^{\mathrm{b}}$ Laboratoire des Multimatériaux et Interfaces (LMI), 43 Bd du 11 Novembre 1918, 69622 Villeurbanne, France
}

\begin{abstract}
Catalytic formulations based on manganese oxides supported on inorganic oxides were developed for the treatment of methylamine-containing aqueous effluents via catalytic wet air oxidation (CWAO). Under the applied reaction conditions $\left(190^{\circ} \mathrm{C}, 50\right.$ bar total pressure $)$ in the presence of heterogeneous $\beta-\mathrm{MnO}_{2}-$ supported catalysts, formate and ammonium ions were detected as primary products. As the reaction proceeded, a complete mineralization of formate ions was observed while ammonium ions accumulated in the reaction media. The catalytic formulations elaborated in this work were shown to be stable under the applied reaction conditions without any significant leaching of the active phase.
\end{abstract}

\section{Introduction}

Pollutants in water might be eliminated via wet air oxidation (WAO) using oxygen at elevated pressure and temperature. The objective is either to make the effluent biodegradable or to achieve full mineralization of the contaminants by converting the nitrogen and carbon fractions into $\mathrm{N}_{2}, \mathrm{CO}_{2}$ and water. The implementation of a suitable catalyst is known to increase the applicability of the WAO process [1,2]. Supported noble metal catalysts were shown to be highly active and selective to $\mathrm{N}_{2}$ and $\mathrm{CO}_{2}$ for many different organic compounds [2,3]. However, a drastic leaching of the active phase into the aqueous phase was recently evidenced in the case of primary amine-containing effluents [4]. This phenomenon was almost unambiguously attributed to the presence of a lone-pair of electrons localized on the nitrogen atom. The acidification of the reaction medium, in order to protonate the $\mathrm{N}$-atom and decrease the affinity with the metal, suppressed the leaching but also inhibited the reaction. To overcome this problem, by decreasing the affinity between the active phase and the lone pair of electrons on the nitrogen atom, transition metal oxide based catalysts have been developed. Manganese was selected since it exists with many oxidation states and it was demonstrated to have excellent redox properties. Furthermore, some formulations containing manganese have already demonstrated some potential in the WAO

\footnotetext{
* Corresponding author. Tel.: +33 47244 5307; fax: +33 472445399. E-mail address: claude.descorme@ircelyon.univ-lyon1.fr (C. Descorme).
}

of model organic compounds [5,6]. In this study, $\mathrm{MnO}_{2}$ was supported on various oxides $\left(\mathrm{TiO}_{2}, \mathrm{ZrO}_{2}, \mathrm{Ce}_{0.7} \mathrm{Zr}_{0.3} \mathrm{O}_{2}\right.$, and $\left.\mathrm{CeO}_{2}\right)$ and evaluated in the CWAO of methylamine $\left(\mathrm{CH}_{3}-\mathrm{NH}_{2}\right)$. These supports were selected since they were earlier shown to be thermally and chemically stable under the applied reaction conditions. As a simple nitrogen and carbon organic containing molecule, methylamine was chosen as a model molecule. Furthermore methylamine is widely used in the chemical industry and frequently detected as a by-product in the production of pesticides, surfactants, dyes and pharmaceuticals $[7,8]$.

\section{Experimental}

\subsection{Preparation of the catalysts}

All catalysts have been prepared by impregnation of four different commercial supports: $\mathrm{TiO}_{2}$ DT51, $99 \mathrm{~m}^{2} \mathrm{~g}^{-1}, 100 \%$ anatase (tetragonal) from Millenium; $\mathrm{ZrO}_{2}, 126 \mathrm{~m}^{2} \mathrm{~g}^{-1}$, mainly monoclinic and slightly tetragonal from Melcat Chemicals; $\mathrm{Ce}_{0.7} \mathrm{Zr}_{0.3} \mathrm{O}_{2}$, $140 \mathrm{~m}^{2} \mathrm{~g}^{-1}$, cubic solid solution from Rhodia Electronics and Catalysis; and $\mathrm{CeO}_{2} \mathrm{HSA} 5,230 \mathrm{~m}^{2} \mathrm{~g}^{-1}$, cubic from Rhodia Electronics and Catalysis. The commercial supports were suspended in an aqueous solution of $\mathrm{Mn}\left(\mathrm{NO}_{3}\right)_{2} \cdot 4 \mathrm{H}_{2} \mathrm{O}$ (Alfa-Aesar). The amount of manganese salt was calculated to achieve a $12 \mathrm{wt}$.\% loading in $\mathrm{Mn}$. The water was then slowly evaporated at $60^{\circ} \mathrm{C}$ under stirring to obtain a powder which was dried at $100^{\circ} \mathrm{C}$ overnight and finally calcined in a muffle furnace under static air at $350^{\circ} \mathrm{C}$ for $4 \mathrm{~h}$. 


\subsection{Characterization of the catalysts}

Powder X-ray diffraction (XRD) patterns were acquired on a Bruker D8 Advance A25 diffractometer using the $\mathrm{Cu} \mathrm{K} \alpha$ radiation $(\lambda=1.541 \AA)$. Diffractograms were collected in the $2 \theta=10-85^{\circ}$ range with a scanning speed of $0.01^{\circ} \mathrm{s}^{-1}$. The $\mathrm{X}$-ray tube was operated at $50 \mathrm{kV}, 35 \mathrm{~mA}$. The XRD crystallographic phases were identified using ICDD-JCPDS data files.

Surface area measurements were carried out with a nitrogen sorption Sorptomatic 1990 (CE Instruments) analyzer. Before measurements, samples were evacuated for $12 \mathrm{~h}$ at $70^{\circ} \mathrm{C}$ under primary vacuum. Adsorption-desorption measurements were performed at $-196^{\circ} \mathrm{C}$. The surface area was determined by the Brunauer-Emmett-Teller (BET) approach. The pore size distribution and the porous volume were calculated from the adsorption branch of the isotherms using the Barrett-Joyner-Halenda (BJH) method. SEM images were acquired on a S800 Hitachi operating at $15 \mathrm{kV}$. TEM images were obtained on a Topcon instrument operating at $200 \mathrm{kV}$. For the TEM observations, the samples were grinded and deposited directly on a copper grid coated with a thin carbon film.

Inductively coupled plasma-optical emission spectroscopy (ICPOES, Activa Horiba JOBIN YVON) was used to measure the manganese loading on the fresh catalyst (before reaction) and the concentration of manganese in the aqueous solution after reaction in order to check for leaching.

\subsection{Catalytic wet air oxidation experiments}

$30 \mathrm{mmol} \mathrm{L}^{-1}$ aqueous solutions of methylamine (MA) were prepared by dilution in ultra-pure water of a $40 \mathrm{wt}$.\% methylamine solution purchased from Sigma-Aldrich. Catalytic wet air oxidation (CWAO) experiments were performed in a $300 \mathrm{~mL}$ batch reactor made of Hastelloy C22 [9,10]. The reactor is equipped with a magnetically driven stirrer set at $1250 \mathrm{rpm}$ to avoid any mass transfer limitations in the liquid phase. Temperature was kept constant at $190^{\circ} \mathrm{C}$ with a PID electronic controller. $150 \mathrm{~mL}$ of a $30 \mathrm{mmol} \mathrm{L}^{-1}$ methylamine solution was introduced into the reactor with $0.3 \mathrm{~g}$ of catalyst. After purging with argon to remove any trace of air, a 7 bar pressure of argon was maintained in the reactor before heating, to prevent any boiling phenomenon. The reactor was heated to $190^{\circ} \mathrm{C}$ in $30 \mathrm{~min}$. Air was then introduced into the reactor up to 50 bar total pressure (partial pressure of $\mathrm{O}_{2}=5.4$ bar) and stirring was started. This time was considered to be the zero time for the reaction. Liquid samples were periodically withdrawn from the reactor, centrifuged and filtered through $0.45 \mu \mathrm{m}$ syringe filters. After sampling, the pressure in the reactor was carefully adjusted to keep the total pressure constant all along the experiment.

\subsection{Samples analysis}

Upon CWAO of methylamine over the prepared catalysts, the two major primary degradation products in the aqueous solution were the ammonium and formate ions formed upon cleavage of the $\mathrm{C}-\mathrm{N}$ bond in MA. Nitrate and nitrite ions were also formed but in much smaller quantities as described in Sections 3.1 and 3.2.

These ions were analyzed using an ion chromatograph (Metrohm 881 IC Pro) equipped with both a cationic (Metrosep C4 150/4.0) and an anionic column (Metrosep A Supp 5 150/4.0). The elutants for the cations and the anions separation were $\mathrm{HNO}_{3}(1.7 \mathrm{mmol} \mathrm{L}-1) /$ dipicolinic acid $(0.7 \mathrm{mmol} \mathrm{L}-1)$ and $\mathrm{Na}_{2} \mathrm{CO}_{3}\left(3.2 \mathrm{mmol} \mathrm{L}^{-1}\right) / \mathrm{NaHCO}_{3}\left(1 \mathrm{mmol} \mathrm{L}^{-1}\right)$, respectively. Calibrations were carried out using methylamine hydrochloride, ammonium chloride, sodium nitrate, sodium nitrite and formic acid solution (Sigma-Aldrich).

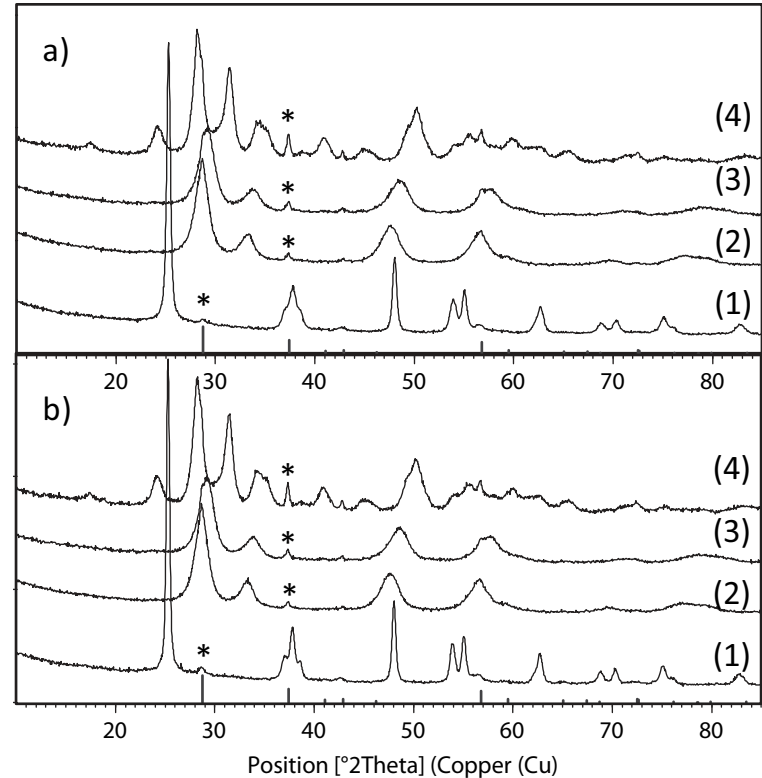

Fig. 1. XRD patterns of the catalysts $\left(1-\mathrm{MnO}_{2} / \mathrm{TiO}_{2} ; 2-\mathrm{MnO}_{2} / \mathrm{CeO}_{2} ; 3-\right.$ $\mathrm{MnO}_{2} / \mathrm{Ce}_{0.7} \mathrm{Zr}_{0.3} \mathrm{O}_{2} ; 4-\mathrm{MnO}_{2} / \mathrm{ZrO}_{2}$ ) before reaction (a) and after reaction (b). [Vertical blue lines on the $x$ axis correspond to the diffraction peaks of pyrolusite (JCPDS-ICDD card no. 04-007-3893); diffraction lines marked with an asterisk ${ }^{*}$ ) are characteristic of the $\beta-\mathrm{MnO}_{2}$ pyrolusite phase.]

The total organic carbon (TOC) and the total nitrogen (TN) were measured on a TOC-VCSH analyzer coupled with a TN unit (TNM-1) from Shimadzu.

The amount of $\mathrm{CO}_{2}$ and $\mathrm{N}_{2}$ produced could be estimated from the difference between the amount of $\mathrm{C}$ and $\mathrm{N}$ initially introduced in the reactor as MA and the total concentration in carbon and nitrogen containing compounds in the liquid phase at any time.

Furthermore, to check whether all intermediates and products had been properly identified and quantified, the $\mathrm{C}$ and $\mathrm{N}$ mass balances were assessed by comparison between the TOC and TN values and the ion chromatography results.

\section{Results and discussion}

\subsection{Catalyst characterizations}

Fig. 1 shows the XRD diffractograms of the different catalysts before (a) and after (b) catalytic wet air oxidation of MA. Manganese was detected in all cases as a tetragonal $\beta-\mathrm{MnO}_{2}$ pyrolusite phase (JCPDS-ICDD card no. 01-072-1984). The peaks marked with an asterisk $\left({ }^{*}\right)$ could be unambiguously attributed to the $\beta-\mathrm{MnO}_{2}$ phase and not to the support. However, although manganese is mainly detected as Mn(IV) both before and after reaction, one cannot conclude that $\mathrm{Mn}(\mathrm{IV})$ is the active species during the reaction. Indeed, a redox mechanism is proposed to be involved upon oxidation of methylamine and manganese would probably cycle between $\mathrm{Mn}(\mathrm{IV})$ and $\mathrm{Mn}(\mathrm{III})$ upon reaction.

The $\mathrm{Ce}_{0.7} \mathrm{Zr}_{0.3} \mathrm{O}_{2}$ support was demonstrated to be a solid solution with the incorporation of the zirconium ions into the cubic lattice of ceria. Due to the smaller size of the zirconium ions $\left(\mathrm{Zr}^{4+}\right.$ diameter: $0.84 \AA)$ in comparison with the cerium ions $\left(\mathrm{Ce}^{4+}\right.$ diameter: $0.97 \AA$ ), the incorporation of the $\mathrm{Zr}^{4+}$ ions involves a reduction of the lattice parameter, characterized by a shift of all of the ceria diffraction peaks toward higher angles, as observed from the comparison of patterns (2) and (3) in Fig. 1a [11-13].

The $\beta-\mathrm{MnO}_{2}$ phase appeared even more crystalline after the catalytic test than before. The same trend was also observed for the $\mathrm{TiO}_{2}, \mathrm{ZrO}_{2}, \mathrm{CeO}_{2}$ and $\mathrm{Ce}_{0.7} \mathrm{Zr}_{0.3} \mathrm{O}_{2}$ supports, although 

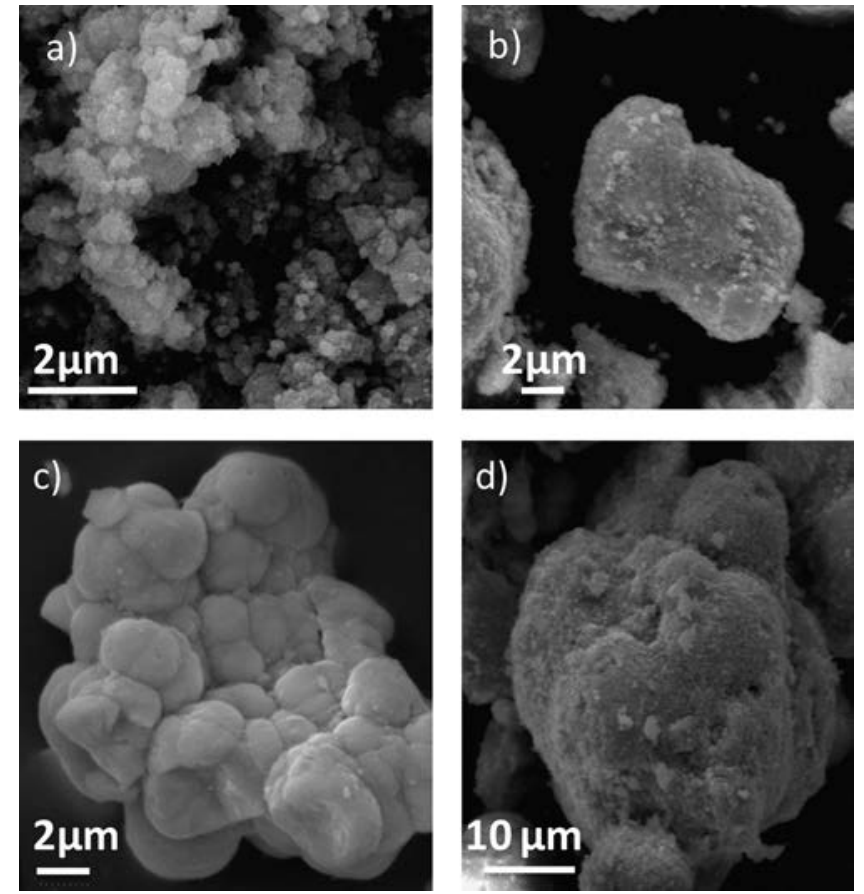

Fig. 2. SEM images of the fresh catalysts $\left(\mathrm{a}-\mathrm{MnO}_{2} / \mathrm{TiO}_{2} ; \mathrm{b}-\mathrm{MnO}_{2} / \mathrm{ZrO}_{2} ; \mathrm{c}-\right.$ $\mathrm{MnO}_{2} / \mathrm{CeO}_{2} ; \mathrm{d}-\mathrm{MnO}_{2} / \mathrm{Ce}_{0.7} \mathrm{Zr}_{0.3} \mathrm{O}_{2}$ ) before reaction.

their crystalline structure was not affected upon reaction. The size of the $\beta-\mathrm{MnO}_{2}$ crystallites was calculated according to the Debye-Scherrer equation based on the (101) diffraction line at $37^{\circ}$, except for the $\mathrm{MnO}_{2} / \mathrm{TiO}_{2}$ catalyst where the (110) line at $29^{\circ}$ was used. The $\beta-\mathrm{MnO}_{2}$ crystallite size was ca. $20 \mathrm{~nm}$ for all catalysts.

The catalysts specific surface area, pore diameter and pore volume are listed in Table 1. The impregnation of manganese on the different supports induced some modifications of the specific surface area and the pore volume compared to the bare support, especially in the case of $\mathrm{CeO}_{2}$. This later observation was related to the partial obstruction of the mesoporous structure with the manganese particles. This phenomenon was more pronounced for the supports with the smallest mesopores.

The SEM images of the fresh catalysts (before test) are presented in Fig. 2. In all cases, the catalyst particles appeared to be pretty much aggregated. The smallest aggregates were observed for the $\mathrm{MnO}_{2} / \mathrm{TiO}_{2}$ catalyst, with a mean size below $1 \mu \mathrm{m}$. On the opposite, the $\mathrm{MnO}_{2} / \mathrm{Ce}_{0.7} \mathrm{Zr}_{0.3} \mathrm{O}_{2}$ sample showed the biggest aggregates with a mean size around $10 \mu \mathrm{m}$. In turn, the $\mathrm{MnO}_{2} / \mathrm{CeO}_{2}$ sample exhibited highly clustered 2-10 $\mu \mathrm{m}$ granules and the $\mathrm{MnO}_{2} / \mathrm{ZrO}_{2}$ catalyst showed the largest aggregate size distribution $(1-20 \mu \mathrm{m})$. The overall morphology of the catalysts did not change after catalytic test (not shown) but the average size of the aggregates slightly increased.

Fig. 3 shows the TEM images of the $\mathrm{MnO}_{2} / \mathrm{CeO}_{2}$ sample which will be shown later to be the most active catalyst. The ceria nanoparticles were shown to be smaller than $10 \mathrm{~nm}$ and the $\beta$ $\mathrm{MnO}_{2}$ particles (pyrolusite) appeared to be as big as a few hundred nanometers in size [14]. The selected area electron diffraction (SAED) pattern further suggested an epitaxial growth of manganese on ceria upon impregnation (good match between the (111) and (110) planes from ceria and $\beta-\mathrm{MnO}_{2}$, respectively), resulting after treatment in a preferential orientation of the cubic ceria nanocrystallites on the large $\beta-\mathrm{MnO}_{2}$ particles.
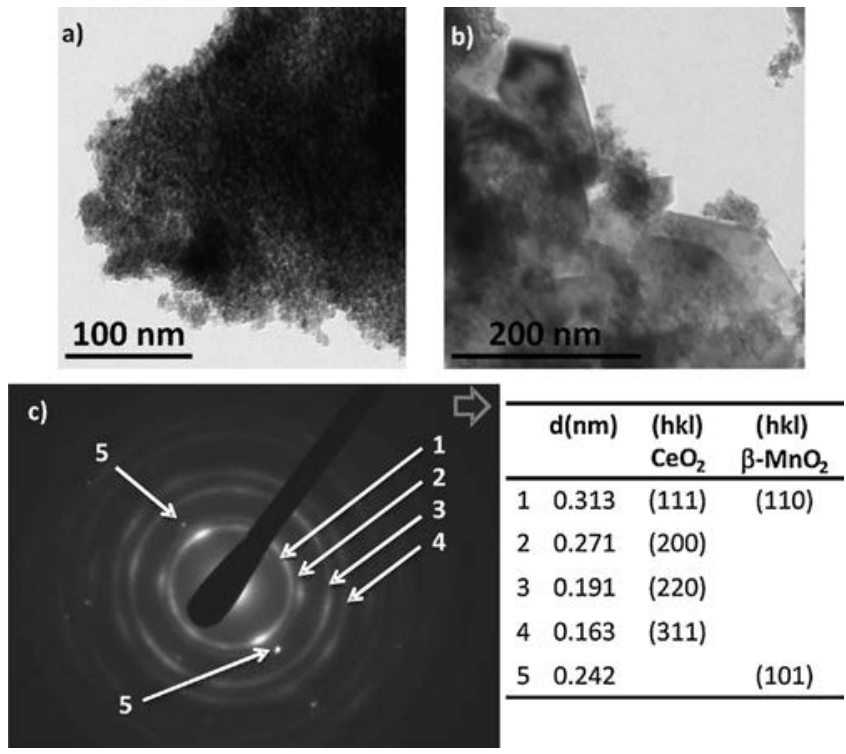

Fig. 3. TEM images of the $\mathrm{MnO}_{2} / \mathrm{CeO}_{2}$ catalyst before reaction ( $\mathrm{a}$ and $\mathrm{b}$ ) and SAED pattern (c) obtained from the area in image (a).

\subsection{Non-catalytic wet air oxidation of methylamine}

Complete mineralization of methylamine (Eq. (1)) implies a $\mathrm{O}_{2}$ :MA molar ratio of 4.5. Under the applied reaction conditions, the amount of oxygen available in the reactor accounted for $103 \%$ of the stoichiometric concentration necessary to achieve complete oxidation of methylamine to $\mathrm{CO}_{2}, \mathrm{~N}_{2}$ and $\mathrm{H}_{2} \mathrm{O}$.

$\mathrm{CH}_{3}-\mathrm{NH}_{2}+9 / 4 \mathrm{O}_{2} \rightarrow \mathrm{CO}_{2}+1 / 2 \mathrm{~N}_{2}+5 / 2 \mathrm{H}_{2} \mathrm{O}$

A blank experiment was first carried out under air, in the absence of any catalyst, to check the stability of methylamine (not shown). Upon heating under argon, 15\% MA was vaporized into the gas phase. This value was in good agreement with the thermodynamic calculations which were performed taking into account the variation of the water ionization constant, $K_{e}$, the acido-basic constant, $K_{B}$ and the Henry's constant, $K_{H}$ with temperature [15]. Furthermore, this test confirmed that no thermal degradation occurred under argon.

In the absence of any catalyst, 58\% methylamine conversion was achieved after $30 \mathrm{~h}$ of reaction under air. At the end of the reaction, the concentration of ammonium ions was $8 \mathrm{mmol} \mathrm{L}^{-1}$, while the concentration of formate, nitrate and nitrite ions was lower than $1 \mathrm{mmol} \mathrm{L}^{-1}$.

To check whether or not some degradation products had been stripped into the gas phase during the reaction, some analysis were also performed on the liquid phase after cooling down the reactor to room temperature. Since no significant difference was ever observed, we assumed that only $\mathrm{CO}_{2}$ and $\mathrm{N}_{2}$ were produced in the gas phase. As a result, the amount of $\mathrm{CO}_{2}$ and $\mathrm{N}_{2}$ produced upon reaction was calculated from the difference between the amount of $\mathrm{C}$ and $\mathrm{N}$ initially introduced in the reactor as MA and the total concentration in carbon and nitrogen-containing compounds in the liquid phase at any time (Fig. 4).

Moreover, from the comparison of the TOC and TN measurements with ion chromatography results, we concluded that all the products had been properly identified and quantified. Indeed, the maximum relative discrepancy was ca. $8 \%$ while important uncertainties were associated with the high dilution levels required before ion chromatography analysis.

Finally, pH measurements were also performed on each sample. $\mathrm{pH}$ decreased upon reaction due to the partial degradation of 
Table 1

Textural characteristics of the different catalysts.

\begin{tabular}{|c|c|c|c|}
\hline Catalysts & BET surface area $\left(\mathrm{m}^{2} \mathrm{~g}^{-1}\right)$ & Pore diameter $(\mathrm{nm})$ & Pore volume, $\left(\mathrm{cm}^{3} \mathrm{~g}^{-1}\right)$ \\
\hline $\mathrm{MnO}_{2} / \mathrm{TiO}_{2}$ & $79(99)^{\mathrm{a}}$ & 13 & 0.26 \\
\hline $\mathrm{MnO}_{2} / \mathrm{ZrO}_{2}$ & $89(126)^{\mathrm{a}}$ & 6 & 0.14 \\
\hline $\mathrm{MnO}_{2} / \mathrm{Ce}_{0.7} \mathrm{Zr}_{0.3} \mathrm{O}_{2}$ & $160(140)^{\mathrm{a}}$ & 10 & 0.19 \\
\hline $\mathrm{MnO}_{2} / \mathrm{CeO}_{2}$ & $170(230)^{\mathrm{a}}$ & 4 & 0.15 \\
\hline
\end{tabular}

a Specific surface area of the bare support, before impregnation $\left(\mathrm{m}^{2} \mathrm{~g}^{-1}\right)$.

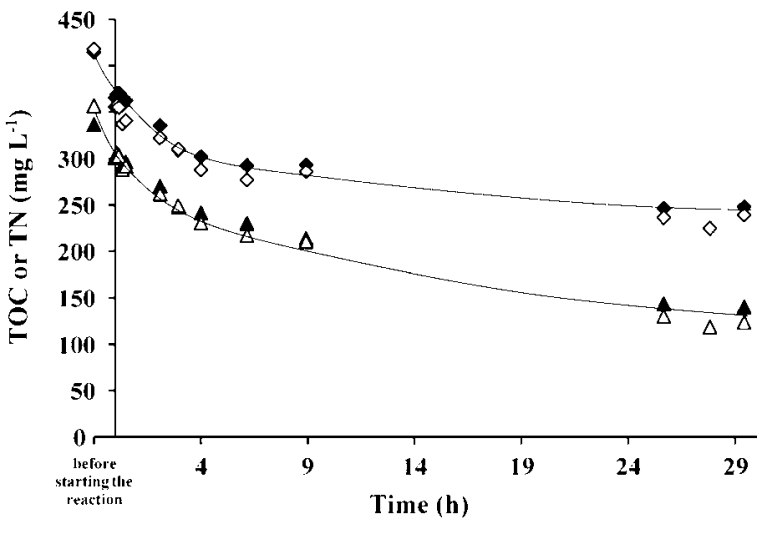

Fig. 4. Non-catalytic wet air oxidation of methylamine $\left(190^{\circ} \mathrm{C}, 30 \mathrm{mmol} \mathrm{L}^{-1}\right.$, $150 \mathrm{~mL}, 50$ bar total pressure): evolutions of the TOC and TN content either directly measured $(\Lambda, \downarrow)$ or calculated from the ion chromatography data $(\triangle, \diamond)$.

methylamine ( $\left.\mathrm{p} K_{\mathrm{a}}=10.6\right)$ and the formation of less basic refractory compounds such as ammonia $\left(\mathrm{p} K_{\mathrm{a}}=9.3\right)$.

The bare supports were also evaluated independently but did not show any activity, except for those containing cerium. The initial specific reaction rate was calculated to be 0.8 and $0.9 \mathrm{~mol}_{\mathrm{MA}} \mathrm{h}^{-1} \mathrm{~g}_{\mathrm{cata}}{ }^{-1}$ in the case of $\mathrm{Ce}_{0.7} \mathrm{Zr}_{0.3} \mathrm{O}_{2}$ and $\mathrm{CeO}_{2}$, respectively. Indeed, ceria-based catalysts are widely used in oxidation reactions, especially because of their redox properties associated to the $\mathrm{Ce}^{3+} / \mathrm{Ce}^{4+}$ centers. High oxygen mobility was evidenced in such systems [16-18].

\subsection{Catalytic wet air oxidation of methylamine}

In the presence of a catalyst, the degradation of methylamine was much faster but occurred at different rates depending on the catalyst formulation, as shown in Fig. 5. The $\mathrm{MnO}_{2} / \mathrm{CeO}_{2}$ catalyst appeared to be markedly more active compared to the others (Table 2). The initial specific reaction rate of $\mathrm{MnO}_{2} / \mathrm{CeO}_{2}$

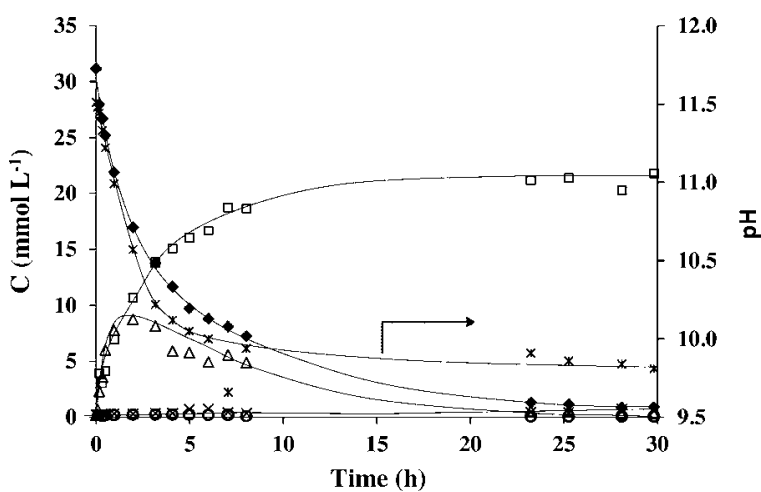

Fig. 5. Typical results obtained upon catalytic wet air oxidation of methylamine $\left(190^{\circ} \mathrm{C}, 30 \mathrm{mmol} \mathrm{L}^{-1}, 150 \mathrm{~mL}, 50\right.$ bar total pressure, $\left.0.3 \mathrm{~g} \mathrm{MnO}_{2} / \mathrm{ZrO}_{2}\right)$ : evolution of the concentration of the different species in solution as a function of time [methylamine $(\bullet)$, ammonium $(\square)$, formate $(\times)$ nitrate $(\triangle)$, nitrite $(\bigcirc)$ and $\mathrm{pH}\left({ }^{*}\right.$, right axis)].

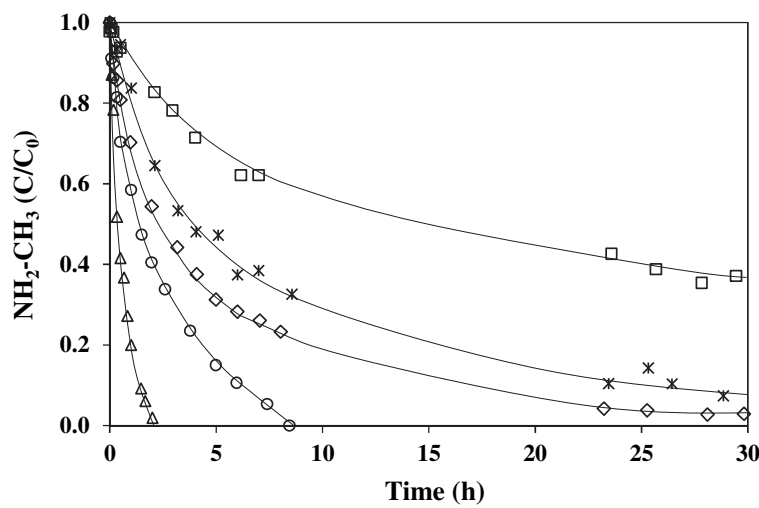

Fig. 6. Catalytic wet air oxidation of methylamine $\left(190^{\circ} \mathrm{C}, 30 \mathrm{mmol} \mathrm{L}^{-1}, 150 \mathrm{~mL}\right.$ 50 bar total pressure, $0.3 \mathrm{~g}$ of catalyst): evolution of the relative concentration of methylamine $\left(C / C_{0}\right)$ as a function of time in the absence or in the presence of a catalyst [no catalyst $(\square) ; \mathrm{MnO}_{2} / \mathrm{TiO}_{2}\left({ }^{*}\right) ; \mathrm{MnO}_{2} / \mathrm{ZrO}_{2}(\diamond) ; \mathrm{MnO}_{2} / \mathrm{Ce}_{0.7} \mathrm{Zr}_{0.3} \mathrm{O}_{2}(\bigcirc)$; $\left.\mathrm{MnO}_{2} / \mathrm{CeO}_{2}(\triangle)\right]$

was calculated to be $17 \mathrm{~mol}_{\mathrm{MA}} \mathrm{h}^{-1} \mathrm{~g}_{\mathrm{cata}}{ }^{-1}$. Complete conversion of methylamine was achieved in less than $2 \mathrm{~h}$.

In all cases, ammonium and formate ions were produced in stoichiometric amounts at the very beginning of the reaction, as shown in Fig. 6 where the typical evolutions of the concentrations of methylamine and the different products are represented. This observation suggested that the first step of the oxidation process was the cleavage of the $\mathrm{C}-\mathrm{N}$ bond, leading to those two primary products in the liquid phase (Eq. (2)).

$\mathrm{CH}_{3}-\mathrm{NH}_{2}\left(+\mathrm{O}_{2}\right) \rightarrow \mathrm{HCCO}^{-}+\mathrm{NH}_{4}{ }^{+} \rightarrow \mathrm{CO}_{2}, \mathrm{H}_{2} \mathrm{O}, \mathrm{N}_{2}, \mathrm{NO}_{2}{ }^{-}, \mathrm{NO}_{3}-$

Upon further reaction, the formate ions concentration reached a maximum before being totally mineralized to $\mathrm{CO}_{2}$. This evolution was confirmed by the TOC measurements (Fig. 7). Noteworthy, considering the $\mathrm{pH}$ conditions, formic acid was present as formate

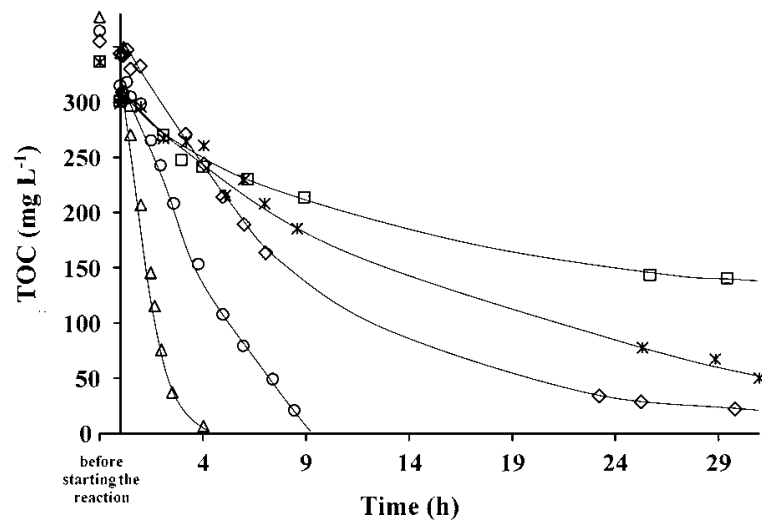

Fig. 7. Catalytic wet air oxidation of methylamine $\left(190^{\circ} \mathrm{C}, 30 \mathrm{mmol} \mathrm{L}^{-1}, 150 \mathrm{~mL}\right.$ 50 bar total pressure, $0.3 \mathrm{~g}$ of catalyst): evolution of the total organic carbon as a function of time [no catalyst $(\square) ; \mathrm{MnO}_{2} / \mathrm{TiO}_{2}\left(^{*}\right) ; \mathrm{MnO}_{2} / \mathrm{ZrO}_{2}(\diamond) ; \mathrm{MnO}_{2} / \mathrm{Ce}_{0.7} \mathrm{Zr}_{0.3} \mathrm{O}_{2}$ $\left.(\bigcirc) ; \mathrm{MnO}_{2} / \mathrm{CeO}_{2}(\triangle)\right]$ 
Table 2

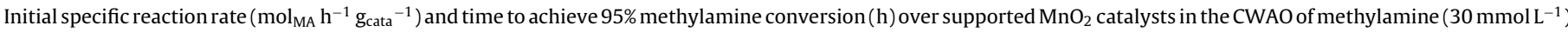
at $190^{\circ} \mathrm{C}$ under 50 bar total pressure.

\begin{tabular}{|c|c|c|c|c|}
\hline & $\mathrm{MnO}_{2} / \mathrm{TiO}_{2}$ & $\mathrm{MnO}_{2} / \mathrm{ZrO}_{2}$ & $\mathrm{MnO}_{2} / \mathrm{Ce}_{0.7} \mathrm{Zr}_{0.3} \mathrm{O}_{2}$ & $\mathrm{MnO}_{2} / \mathrm{CeO}_{2}$ \\
\hline$r_{0}\left(\mathrm{~mol}_{\mathrm{MA}} \mathrm{h}^{-1} \mathrm{~g}_{\text {cata }}{ }^{-1}\right)^{\mathrm{a}}$ & 2 & 6 & 10 & 17 \\
\hline $95 \%$ MA conversion $(h)^{\mathrm{b}}$ & 30 & 23 & 7 & 2 \\
\hline
\end{tabular}

a Calculated in the first $0.5 \mathrm{~h}$, at low methylamine conversion.

b Calculated with respect to the initial concentration of methylamine introduced in the reactor.

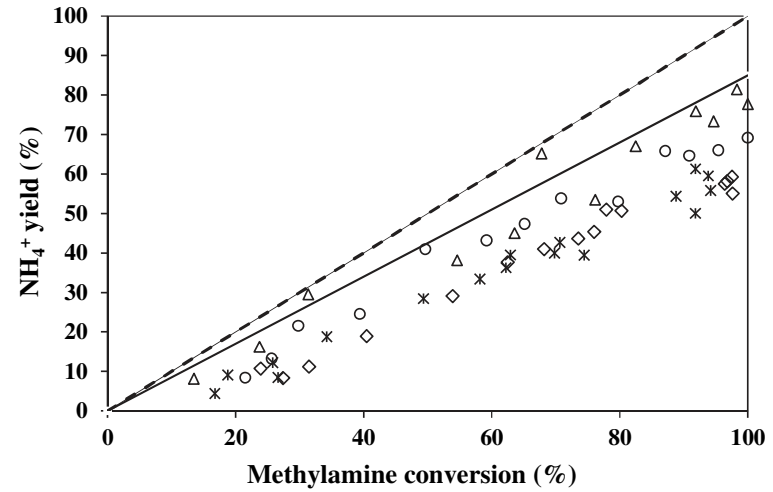

Fig. 8. Evolution of the yield to ammonium ions as a function of the overall methylamine conversion upon catalytic wet air oxidation of methylamine $\left(190{ }^{\circ} \mathrm{C}, 30 \mathrm{mmol} \mathrm{L}^{-1}, 150 \mathrm{~mL}, 50\right.$ bar total pressure, $0.3 \mathrm{~g}$ of catalyst) $\left[\mathrm{MnO}_{2} / \mathrm{TiO}_{2}\right.$ $\left.{ }^{*}\right) ; \mathrm{MnO}_{2} / \mathrm{ZrO}_{2}(\diamond) ; \mathrm{MnO}_{2} / \mathrm{Ce}_{0.7} \mathrm{Zr}_{0.3} \mathrm{O}_{2}(\bigcirc) ; \mathrm{MnO}_{2} / \mathrm{CeO}_{2}(\triangle)$ ]. (NB: see Section 3.3 for the explanations on the dotted and full lines.)

ions which appeared to be much less reactive compared to the molecular form. As a result, formic acid could be detected as an intermediate.

On the contrary, the ammonium ions appeared to be refractory toward further oxidation and kept accumulating in the reaction mixture upon reaction. Nitrates and nitrites were also identified in trace amounts.

Fig. 8 shows the evolution of the yield in ammonium ions as a function of the overall methylamine conversion. If all the nitrogen atoms in MA would be selectively converted into $\mathrm{NH}_{4}{ }^{+}$, all the data points would fall on the bisecting line on the graph (dotted line in Fig. 8). However, since 15\% methylamine was vaporized upon heating and the overall methylamine conversion was calculated with respect to the initial concentration of methylamine introduced in the reactor, the maximum yield in $\mathrm{NH}_{4}{ }^{+}$is $85 \%$. Consequently, in our case, if the conversion in $\mathrm{NH}_{4}{ }^{+}$would be $100 \%$ selective, the data points would fall on the full line drawn in Fig. 8. In total, the initial yield in ammonium varied between $50 \%$ and $80 \%$, corresponding in the later case to an almost totally selective conversion of MA in the liquid phase to $\mathrm{NH}_{4}{ }^{+}$. In addition, we could conclude from the TN measurements that the selectivity to $\mathrm{N}_{2}$ ranged between 30 and $50 \%$ after $30 \mathrm{~h}$ reaction (Fig. 9).

Furthermore, taking into account of the fact that the size of $\mathrm{MnO}_{2}$ crystallites (i.e. the dispersion of the active phase) was more or less the same for all catalysts (Section 3.3), the differences in activity of the different catalysts could be attributed to the effect of the support.

As reported in Section 3.1, bare $\mathrm{CeO}_{2}$ was already demonstrated to be active in the CWAO of methylamine, although the activity was much limited compared to the $\mathrm{MnO}_{2} / \mathrm{CeO}_{2}$ catalyst. Pure $\mathrm{MnO}_{2}\left(S=10 \mathrm{~m}^{2} \mathrm{~g}^{-1}\right)$ was also evaluated in the CWAO of MA and the initial specific reaction rate was calculated to be ca. $16 \mathrm{~mol}_{\mathrm{MA}} \mathrm{h}^{-1} \mathrm{~g}_{\mathrm{cata}}{ }^{-1}$. Taking into account that the manganese loading in the $\mathrm{MnO}_{2} / \mathrm{CeO}_{2}$ catalyst was only $12 \mathrm{wt}$.\%, the $\mathrm{MnO}_{2} / \mathrm{CeO}_{2}$ catalyst appeared to be much more active than the linear combination of the activities of the bare ceria and pure $\mathrm{MnO}_{2}$, respectively.

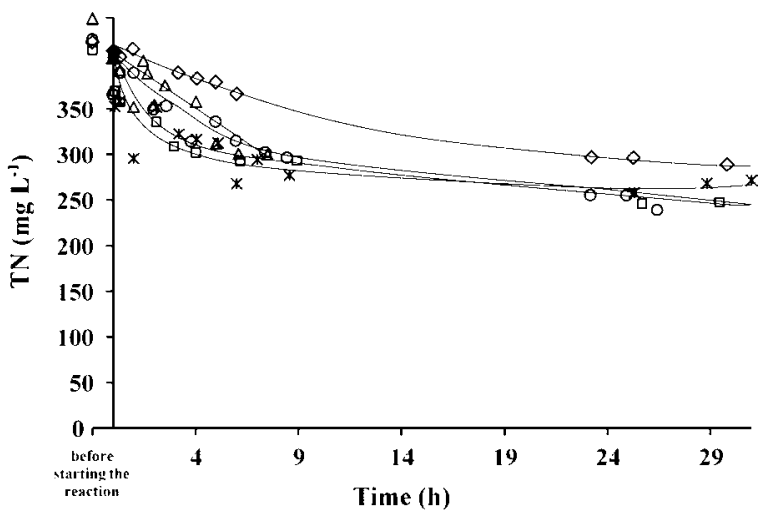

Fig. 9. Evolution of the total nitrogen (TN) content measured upon catalytic wet air oxidation of methylamine $\left(190^{\circ} \mathrm{C}, 30 \mathrm{mmol} \mathrm{L}^{-1}, 150 \mathrm{~mL}, 50\right.$ bar total pressure, $0.3 \mathrm{~g}$ of catalyst) [no catalyst $(\square) ; \mathrm{MnO}_{2} / \mathrm{TiO}_{2}\left(^{*}\right) ; \mathrm{MnO}_{2} / \mathrm{ZrO}_{2}(\diamond) ; \mathrm{MnO}_{2} / \mathrm{Ce}_{0.7} \mathrm{Zr}_{0.3} \mathrm{O}_{2}(\bigcirc)$; $\left.\mathrm{MnO}_{2} / \mathrm{CeO}_{2}(\triangle)\right]$.

Conclusively, a synergetic effect between the ceria and manganese oxide phases was unambiguously evidenced, probably because of promotion of the redox properties of the system when combining ceria and manganese which may exist at different oxidation states. Indeed, a synergetic effect between ceria and manganese oxides was already reported in the literature by different authors [19-21]. However, the redox properties of these solids would have to be studied in deeper details in order to confirm this hypothesis.

The same hypothesis would apply for the $\mathrm{MnO}_{2} / \mathrm{Ce}_{0.7} \mathrm{Zr}_{0.3} \mathrm{O}_{2}$ catalyst which was unambiguously shown to be significantly more active than the $\mathrm{MnO}_{2} / \mathrm{ZrO}_{2}$ catalyst. However, the number of reducible centers in the $\mathrm{Ce}_{0.7} \mathrm{Zr}_{0.3} \mathrm{O}_{2}$ support (i.e. the number of cerium atoms) being only 70 at.\% compared to pure ceria, the synergetic effect would be less pronounced.

Finally, the chemical stability of the catalyst was checked by measuring the concentration of manganese in the liquid phase at the end of the reaction using ICP-OES. No manganese was ever detected $(<0.1 \mathrm{ppm})$, demonstrating the good stability of these newly developed catalysts in the CWAO of MA. However, long-term experiments under continuous operation conditions would be required to effectively assess the stability of these materials.

\section{Conclusions}

Supported $\beta-\mathrm{MnO}_{2}$ catalysts were investigated in the catalytic wet air oxidation of methylamine. Ammonium and formate ions appeared as the primary products in the CWAO of MA $\left(30 \mathrm{mmol} \mathrm{L}^{-1}\right)$ at $190^{\circ} \mathrm{C}$ under 50 bar total pressure. Nitrate and nitrite ions were also detected in trace amounts. Ammonium ions were refractory and accumulated in the reaction medium while the formate ions were further mineralized to $\mathrm{CO}_{2}$. ICP-OES analysis confirmed the chemical stability of the catalysts under the applied reaction conditions and no significant manganese leaching was ever detected $(<0.1 \mathrm{ppm})$. The $\mathrm{MnO}_{2} / \mathrm{CeO}_{2}$ catalyst, with 
improved redox properties, exhibited the best catalytic performances $\left(17 \mathrm{~mol}_{\mathrm{MA}} \mathrm{h}^{-1} \mathrm{~g}_{\text {cata }}{ }^{-1}\right)$.

\section{Acknowledgements}

This work was financially supported by the Région Rhône-Alpes. The authors gratefully acknowledge the Région Rhône-Alpes for the Ph.D. grant awarded to France Schmit for the period 2011-2014.

\section{References}

[1] V.S. Mishra, V.V. Mahajani, J.B. Joshi, Ind. Eng. Chem. Res. 34 (1995) 2-48

[2] S.K. Bhargava, J. Tardio, J. Prasad, K. Föger, D.B. Akolekar, S.C. Grocott, Ind. Eng. Chem. Res, 45 (2006) 1221-1258.

[3] L. Oliviero, J. Barbier, D. Duprez, Appl. Catal. B: Environ. 40 (2003) 163-184.

[4] N. Grosjean, C. Descorme, M. Besson, Appl. Catal. B: Environ. 97 (2010) 276-283.

[5] F. Arena, C. Italiano, L. Spadaro, Appl. Catal. B: Environ. 115-116 (2012) $336-345$.

[6] A. Cybulski, Ind. Eng. Chem. Res. 46 (2007) 4007-4033

[7] C. Aguilar, R. Garcia, G. Soto-Garrido, R. Arraigada, Top. Catal. 33 (2005) 201-206.
[8] S. Helali, F. Dappozze, S. Horikoshi, T. Hoai Bui, N. Perol, C. Guillard, Photobiol. A: Chem. 255 (2013) 50-57.

[9] A. Pintar, M. Besson, P. Gallezot, Appl. Catal. B: Environ. 31 (2001) 275-290.

[10] D. Pham Minh, P. Gallezot, S. Azabou, S. Sayadi, M. Besson, Appl. Catal. B: Environ. 84 (1) (2008) 749-757.

[11] W. Mista, T. Rayment, J. Hanuza, L. Macalik, Mater. Sci. Pol. 22 (2004) 153-170

[12] M. Yashima, S. Sasaki, Y. Yamaguchi, M. Mori, Appl. Phys. Lett. 72 (1998) $182-184$.

[13] S. Abdollahzadeh-Ghom, C. Zamani, T. Andreu, M. Epifani, J.R. Morante, Appl. Catal. B: Environ. 108-109 (2011) 32-38.

[14] D. Su, H.-J. Ahn, G. Wang, NPG Asia Mater. 5 (2013) 1-7.

[15] R. Sanders, Max-Plank Institute of Chemistry, 2013, December, http://www mpch-mainz.mpg.de/ sander/res/henry.html

[16] D. Duprez, C. Descorme, Oxygen storage/redox capacity and related phenomenon on ceria-based catalysts, in: A. Trovarelli (Ed.), Catalysis by Ceria and Related Materials, vol. 2, Università di Udine, Italy, 2002, pp. 243-276.

[17] H. Li, H. Li, G. Qi, Tana, X. Zhang, W. Li, W. Shen, Catal. Sci. Technol. 1 (2011) $1677-1682$

[18] C. Sun, Energy Environ. Sci. 5 (2012) 8475-8505.

[19] S. Imamura, A. Dol, S. Ishido, Ind. Eng. Chem. Prod. Res. Dev. 24 (1985) 75.

[20] Q. Zhang, C. Qiu, H. Xu, T. Lin, Z. Lin, M. Gong, Y. Chen, Catal. Today 175 (2011) $171-176$.

[21] Z.Y. Ding, L. Li, D. Wade, E.F. Gloyna, Ind. Eng. Chem. Res. 37 (1998) 1707. 